Invited Paper, For, Proceedings, $13^{\text {th }}$ Radiochemical Conference, Marianske Lazne, Czech Republic, April 19-24, 1998, in press.

$$
\text { CONF- } 980446--
$$

\title{
PRODUCTION OF MEDICAL RADIOISOTOPES IN THE ORNL HIGH FLUX ISOTOPE REACTOR (HFIR) FOR CANCER TREATMENT AND ARTERIAL RESTENOSIS THERAPY AFTER PTCA
}

\section{RECEIVED \\ JUN 251998 \\ OSTI}

${ }^{1}$ F. F. (Russ) KNAPP, Jr., 'A. L. BEETS, ${ }^{1}$ S. MIRZADEH, ${ }^{2} \mathrm{C}$. W. ALEXANDER and ${ }^{3}$ R. L. HOBBS

${ }^{\prime}$ Nuclear Medicine Group, Life Sciences Division

${ }^{2}$ Chemical Technology Division

${ }^{2}$ Research Reactors Division Oak Ridge National Laboratory (ORNL)

Oak Ridge, TN 37831-6229, U.S.A.

RECEIVED

MAY 141998

OSTI

For reprints and correspondence contact: F. F. (Russ) Knapp, Jr., Group Leader, Nuclear Medicine, Oak Ridge National Laboratory (ORNL), Building 4501, Mail Stop 6229, P.O. Box 2008, Oak Ridge, TN 37831-6229; Tel. (423) 574-6225; FAX (423) 574-6226; E-mail $<j k p @$ ornl.gov>.

DISTRIBUTION OF THIS DOCUMENT IS UNMMITEO
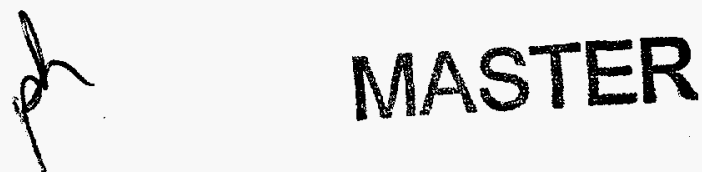

Research at ORNL is supported by the U.S. Department of Energy (DOE), under contract DEAC05-960R22464 with Lockheed Martin Energy Research Corporation. 


\section{DISCLAMMER}

This report was prepared as an account of work sponsored by an agency of the United States Government. Neither the United States Government nor any agency thereof, nor any of their employees, makes any warranty, express or implied, or assumes any legal liability or responsibility for the accuracy, completeness, or usefulness of any information, apparatus, product, or process disclosed, or represents that its use would not infringe privately owned rights. Reference herein to any specific commercial product, process, or service by trade name, trademark, manufacturer, or otherwise does not necessarily constitute or imply its endorsement, recommendation, or favoring by the United States Government or any agency thereof. The views and opinions of authors expressed herein do not necessarily state or reflect those of the United States Government or any agency thereof. 


\section{DISCLAIMER}

Portions of this document may be illegible electronic image products. Images are produced from the best available original document. 


\title{
PRODUCTION OF MEDICAL RADIOISOTOPES IN THE ORNL HIGH FLUX ISOTOPE REACTOR (HFIR) FOR CANCER TREATMENT AND ARTERIAL RESTENOSIS THERAPY AFTER PTCA \\ ${ }^{1}$ F. F. (Russ) KNAPP, Jr., 'A. L. BEETS, ${ }^{1}$ S. MIRZADEH, ${ }^{2} \mathrm{C}$. W. ALEXANDER \\ ${ }^{3}$ R. L. HOBBS \\ ${ }^{\prime}$ Nuclear Medicine Group, Life Sciences Division \\ ${ }^{2}$ Chemical Technology Division \\ ${ }^{2}$ Research Reactors Division \\ Oak Ridge National Laboratory (ORNL) \\ Oak Ridge, TN 37831-6229, U.S.A.
}

\begin{abstract}
The High Flux Isotope Reactor (HFIR) at the Oak Ridge National Laboratory (ORNL) represents an important resource for the production of a wide variety of medical radioisotopes. First beginning operation in 1965, the high thermal neutron flux $\left(2.6 \times 10^{15}\right.$ neutrons $/ \mathrm{cm}^{2} / \mathrm{sec}$ at $\left.85 \mathrm{MW}\right)$ and versatile target irradiation and handling facilities provide the opportunity for production of a wide variety of neutronrich medical radioisotopes of current interest for therapy. In addition to serving as a key production site for californium-252 and other transuranic elements, important examples of therapeutic radioisotopes which are currently routinely produced in the HFIR for distribution include dysprosium-166 (parent of holmium166), rhenium-186, tin-117m and tungsten-188 (parent of rhenium-188). The nine hydraulic tube (HT) positions in the central high flux region permit the insertion and removal of targets at any time during the operating cycle (22-24 days) and have traditionally represented a major site for production of medical radioisotopes. To increase the irradiation capabilities of the HFIR, special target holders have recently been designed and fabricated which will be installed in the six Peripheral Target Positions (PTP), which are also located in the high flux region. These positions are only accessible during reactor refueling and will be used for long-term irradiations, such as required for the production of tin-117m and tungsten-188. Each of the $P T P$ tubes will be capable of housing a maximum of eight $H T$ targets, thus increasing the total maximum number of $H T$ targets from the current nine, to a total of 57 . In this paper the therapeutic use of reactorproduced radioisotopes for bone pain palliation and vascular brachytherapy and the therapeutic medical radioisotope production capabilities of the ORNL HFIR are briefly discussed.
\end{abstract}

Running Title: HFIR Production of medical radioisotopes 


\section{Introduction}

Nuclear reactors continue to play an important role in providing radioisotopes for nuclear medicine [1-2]. Most reactor-produced radioisotopes are "neutron rich" and decay by betaemission and are thus of interest for therapeutic applications (Table 1). Routine clinical applications with therapeutic radioisotopes, include cancer therapy and bone pain palliation [3-4] (Table 2 ), and require reliable availability of the required radioisotopes at reasonable costs. Other important applications include the irradiation of tumors, which has been described extensively elsewhere, and the treatment of rheumatoid arthritis ("radionuclide synovectomy"). In addition, an important new application using both reactor-produced gamma- and in paticular, beta-emitting radioisotopes, is for the inhibition of arterial restenosis following high pressure balloon angioplasty, primary for the coronary vessels [5-8]. Radionuclide generators (Table 3) prepared from reactor-produced radioisotopes are of particular interest since repeated elution can inexpensively provide many patient doses. This aspect is expected to be especially important for providing a source of radioisotopes to remote sites, especially in developing regions, which involve long distances and expensive distribution costs. A major growth area in nuclear medicine is therapy, with both unsealed sources and tissue-targeted radiopharmaceuticals, and there is thus a rapidly increasing requirement for therapeutic radioisotopes, most of which are reactorproduced. With the increasing use of beta-emitting radioisotopes in nuclear medicine, oncology and interventional cardiology, nuclear reactors will play an increasingly important role in providing radioisotopes for these applications. A recent review [9] has summarized the reactors which are available internationally (297 as of 1994) and those which are used for medical radioisotope production. Although a variety of research reactors are operating throughout the world, including several which have moderate to high thermal neutron flux (Table 4), the general trend is that most of these reactors are 20-30 years old, and no new reactors are currently planned, for example, for construction in the U.S. Fortunately, several new reactors are planned for construction in Canada (Nordion; Maple X 1 and 2; expected to begin operation in the year 2000 at 10MW), Australia (HIFAR II; ANSTO; 2005; $10 \mathrm{MW}$ ) and Germany (FRMII; Munich; 2005; 20MW) and will hopefully represent important new resources for medical radioisotope production. The goal of this paper is to briefly review the production and use of several reactor-produced radioisotopes of current interest for bone pain palliation and intravascular brachytherapy, and to discuss the role of the ORNL High Flux Isotope Reactor (HFIR) for the production of many of these radioisotopes. Current upgrades of the HFIR are also described which will in particular permit increased production capabilities of tin-117m and tungsten-188. 


\section{Reactor-Produced Radioisotopes for Bone Pain Palliation}

One major current medical use of reactor-produced radioisotopes is for the treatment of painful skeletal metastases which is often encountered in patients with primary tumors of the breast, prostate and lung [3-4]. Although many of these patients are often "end-stage", the quality of life can be significantly improved with the cessation of intractable pain. The use of therapeutic radioisotopes which localize at metastatic sites has been found to be an inexpensive and effective method for treatment of pain, especially for multiple sites for which the use of external beam irradiation is impractical. Such palliative treatment of patients with advanced metastatic disease to the skeleton can dramatically improve their quality of life, and is important application which has many advantages over traditional use of analgesics and external radiation. There are currently several metastatic-targeted agents radiolabeled with various therapeutic radioisotopes which are in various stages of clinical investigation [3-4]. Most radioisotopes used for bone pain palliation are reactor-produced (Table 2). Key examples produced by single neutron capture of enriched targets include rhenium-186 and samarium-153. In addition, generator systems which provide therapeutic daughter radioisotopes from the decay of reactor-produced parent radioisotopes are also of interest. One important example is rhenium-188, available from generators via decay of reactor-produced tungsten-188. Tin- $117 \mathrm{~m}$ is an example of a reactor-produced radioisotope which decays with the emission of low energy conversion electrons rather than by $\beta^{-}$-decay. Each of these agents and/or radioisotopes has specific advantages and disadvantages, however, and the "ideal" agent for bone pain palliation has not yet been identified.

\section{Reactor-Produced Radioisotopes for Vascular Brachytherapy}

An important new therapeutic strategy in the realm of interventional cardiology is the use of beta and gamma-emitting radioisotopes for intravascular brachytherapy $(I V B)$ for the inhibition of coronary restenosis following high pressure percutaneous transluminal coronary balloon angioplasty $(P T C A)$. Most of the radioisotopes for this application are reactor-produced and the generator-derived beta-emitting radioisotope rhenium-188, is in partciular expected to have important applications. An emerging application we have recently proposed [5-8] which is expected to have very important applications is the use of solutions of rhenium-188 agents for the inhibition of coronary artery restenosis following PTCA. This new and unique approach involves the low pressure intracoronary balloon expansion using solutions of rhenium-188, since solutions offer the most uniform vessel wall radiation dose delivery system. The chemical species which 
are being evaluated for this application include rhenium-188-perrhenate and the rhenium-188MAG3 agent (MAG3 = mercaptoacetyltriglycine) and both these chemical species are rapidly excreted via the urinary bladder in the unlikely event of balloon rupture.

\section{The ORNL High Flux Isotope Reactor (HFIR)}

Research reactors represent important facilities for production of a wide spectrum of radioisotopes for various therapeutic applications. The HFIR is located at the Oak Ridge National Laboratory $(O R N L)$ in Oak Ridge, Tennessee, and has the highest steady-state thermal neutron flux and the highest power density available in the world (Figures 1 and 2). The HFIR was originally designed for the production of transuranium radioisotopes, primarily californium-252 and today is a major resource for nuclear medicine research, and permits the production of very large amounts of high specific activity radioisotopes which cannot be produced at many other sites (Table 1). The HFIR began operation in 1965 and is currently operating at a maximum power of $85 \mathrm{MW}$ with a maximal thermal flux, $2-3 \times 10^{15}$ neutrons $\mathrm{cm}^{2} / \mathrm{sec}$ and resonance/epithermal ratios of $25 / 1$ to $40 / 1$ in the Hydraulic Tube (HT) facility. The current cycle length is $22-24$ days and the HFIR currently operates about ten cycles per year. The HFIR has significant target versatility, with 35 target positions in the high flux trap region (Figures 1 and 2), with one channel housing the hydraulic tube facility which contains sufficient space for a linear array of nine target tubes. The availability of the $H T$ facility in the high flux core position permits the insertion and removal of targets at any time during the operating cycle, allowing great flexibility in production schedules. The Beryllium reflector region also has a number of irradiation positions with large volume which are accessible during reactor refueling.

Because of the importance of having the $H T$ positions available for short term irradiations and the practical importance of increasing the target size (mass), the outer Peripheral Target Positions (PTP), which are located in the outer edge of the target bundle (Figures 2-4), are currently being modified to accept long target containers (Figure 3), each of which will house eight individual $H T$ target tubes. Since there are six PTP positions, the maximum number of $H T$ size targets housed in the PTP positions will total 48, which represents over a five-fold increase from the nine $H T$ targets which can currently be irradiated. Since the PTP targets can only be accessed during refueling when the top of the reactor vessel is removed, these positions are only suitable for longer term, multi-cycle irradiations. The use of $H T$ targets in the PTP tubes is an important 
advantage of this design, since it permits removal of the targets from the PTP tubes in the HFIR pool area, with subsequent transportation to the hot cell processing area using the same carrier which is currently in use. A special "carousel" unit is currently being installed in the HFIR pool for loading and unloading the $H T$ targets from the the $P T P$ units (Figure 4).

\section{Examples of Reactor Production Pathways for Therapeutic Radioisotopes}

Single Neutron Capture Production Pathway - Several useful therapeutic radioisotopes can be produced by this route (Tables 1). Rhenium-186 is a key example of a radioisotope of current interest which is produced by neutron capture of enriched rhenium-185. Although the neutron capture cross section is relatively high, very high specific activity rhenium-186 is required for antibody labeling, which may not be possible with many low flux reactors. However, low specific activity rhenium-186 can be used for preparation of phosphonates (Table 2) for palliative treatment of bone pain from cancer. Because of the high thermal neutron cross-section for the rhenium185( $\mathrm{n}, \gamma)$ rhenium-186 reaction, HFIR irradiation of enriched thenium-185 yields high specific activity rhenium-186. Typical production values for a one week irradiation in the HFIR are 13-15 Curies $/ \mathrm{mg}$ rhenium-185. Samarium-153 is another example of a $\beta^{\circ}$-emitting therapeutic radioisotope for bone pain palliation which can be produced in large amounts with high specific activity in even moderate flux reactors. One agent which is currently under development is the Sm-153-EDTMP phosphonate analogue. Palladium-103 can be reactor-produced by irradiation of enriched palladium-102 and represents a major radioactive implantation device for the treatment of prostatic carcinoma. Iodine-125 is manufactured and used for the same application.

Therapeutic Radioisotopes Available From Beta-Decay of Reactor-Produced Radioisotopes Another useful approach which provides carrier-free radioisotopes for therapy is by "batch" chemical separation of the product formed by $\beta$-decay of the reactor-produced parent. Examples produced via this route include silver-111, arsenic-77 and gold-199. Silver-111 is readily obtained by anion exchange chromatographic separation of palladium-111, and the 7.47 day half-life readily permits shipment to other sites. Silver can be complexed with functionalized tetraazaheterocycles for attachment to antibodies or other therapeutic agents. Arsenic-77 is readily separated from the germanium-77 reactor product and has chemistry similar to phosphorus, permitting preparation of arsonates and other potentially useful species. The last example, gold-199, has been of interest for many years and in carrier-free form can be attached to antibodies. 
Production via Double Neutron Capture - Since yields of radioisotopes produced by the double neutron capture process are proportional to the square of the neutron flux, the reactor neutron flux is an important factor for this common reaction pathway. Two radioisotope parents produced by this process which are of current interest for generator systems (Table 3) are tungsten-188 (parent of rhenium-188) and dysprosium-166 (parent of holmium-166). Holmium-166 can be produced directly from neutron irradiation of holmium-165 (monoisotopic in nature) but longlived holmium-166m [half-life 1,200 years; $810 \mathrm{keV}(57 \%)$ and $712 \mathrm{keV}(54 \%)$ gammas, etc.] is also produced. As an alternative, dysprosium-166 produced from dysprosium-164 [10] provides carrier-free holmium-166 (containing no holmium-166m), which is separated by HPLC methods and is currently used for radiation synovectomy, etc. Rhenium-188 is readily separated from tungsten-188 on alumina (vide infra) and is of interest for a variety of therapeutic applications.

HFIR Production by the Inelastic (n,n') Route From Enriched Tin-117 - Tin- $117 m$ is produced with relatively low specific activity $(5-6 \mathrm{mCi} / \mathrm{mg})$ by neutron irradiation of enriched tin116. Specific activity can be increased in the HFIR by a factor of about 3 by the tin-117(n, n')tin$117 \mathrm{~m}$ inelastic route $(20-22 \mathrm{mCi} / \mathrm{mg})$ [11]. In contrast to the other radioisotopes of current interest for palliation, tin- $117 \mathrm{~m}$ decays by conversion electron emission. The low energy conversion electrons travel only a very limited distance in tissue, which may preclude potential bone marrow depression, which can be a limiting factor with high energy $\beta$-emitting radioisotopes, is precluded. Potential advantages of tin- $117 \mathrm{~m}$ are the absence of high energy beta particles, the emission of a gamma photon of nearly optimal energy for imaging, and high metastatic uptake. Production of tin- $117 m$ in nuclear reactor involves radiative capture by the $(n, \gamma)$ route by

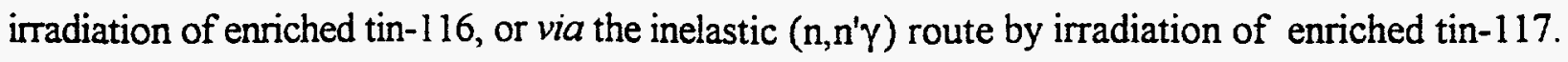
We have evaluated both these routes in detail using the ORNL HFIR [11], where specific activity values of $8-10 \mathrm{mCi} / \mathrm{mg}$ from enriched tin-11.7 after a long irradiation time ( 1 cycle $=24$ days) are routinely obtained. The metallic powder target is shipped directly to customers for processing and preparation of the Sn-117m(IV)-DTPA complex.

\section{Radionuclide Generators Requiring Reactor-Produced Parents}

Radionuclide generators continue to play an important role in nuclear medicine [12-14 ]. Two radionuclide generators which are based on reactor-produced parent radioisotopes which are of current major interest (Table 3) provide dysprosium-166 (dysprosium-165/dysprosium-166) [10] and rhenium-188 (tungsten-188/rhenium-188) [15-19]. 
Rhenium-188 - Rhenium-188 is available carrier-free from a tungsten-188/rhenium-188 generator. The generator which we have developed and optimized at $O R N L$ is a chromatographic system which uses alumina as the adsorbent. Since one of the major issues facing the health care industry is the reduction of costs, a major important advantage for use of rhenium-188 is the inexpensive, ready availability from the generator which has a very long useful shelf-life of several months [1519]. Another advantage is the emission of the $155 \mathrm{keV}$ gamma photon for imaging. There are several rhenium-188-labeled agents which are currently under clinical investigation for bone palliation which include rhenium-188-HEDP and rehnium-188(V)-DMSA (Table 3). We have demonstrated that large, clinical-scale generators loaded with high levels of tungsten-188 $>1$ Curie) provide reproducible high rhenium-188 yields of 75-85\%/bolus and low tungsten-188 parent breakthrough $\left(<10^{-6}\right)$ for periods of several months [15-19]. These studies have demonstrated that the costs of rhenium-188 will be very low on a bolus or unit does basis. Probably the most cost effective approach for using the tungsten-188/rhenium-188 generator would be its use the in a hospital or centralized radiopharmacy, and it remains to be seen if this will be possible.

HFIR Production of Tungsten-188 - We have had extensive experience over the last several years in HFIR production of tungsten-188, from both enriched tungsten-186 tungsten metal and tungsten oxide targets $[16,19-21]$. The metallic powder targets are usually processed by oxidation with hydrogen peroxide and/or hypochlorite in the presence of base and oxide targets are dissolved in base with concomitant oxidation. The reactor production yield of tungsten-188 [16] is about one order of magnitude lower than the calculated values for the W-186(n,y)W-187 $(\sigma=37.9 \pm 0.6$ barns $)$ and $\mathrm{W}-187(\mathrm{n}, \gamma) \mathrm{W}-188(\sigma=64 \pm 10$ barns) reactions. The neutron burn-up cross section for the $\mathrm{W}-188(\mathrm{n}, \gamma) \mathrm{W}-189$ nuclear reaction is one factor which has been recently shown to contribute to the reduced production yields observed for tungsten-188. By irradiation of tungsten-188, a value of $12.0 \pm 2.5$ barns has been calculated for this neutron burn-up cross section [21].

\section{Summary and Conclusions}

Research reactors continue to represent important facilities for production of therapeutic radioisotopes for bone pain palliation. The very high flux of the ORNL HFIR is a unique capability and this reactor represents an important resource for the production of variety of medical radioisotopes, which require a very thermal neutron flux, including several of current interest for bone pain palliation, such as tungsten-188 (i.e. rhenium-188) and tin- $117 m$. 


\section{Acknowledgments}

Research at ORNL is sponsored by the U.S. Department of Energy (DOE), under contract DE-AC05-96OR22464 with Lockheed Martin Energy Research Corporation.

\section{References}

[1] F. F. Knapp, Jr. and S. Mirzadeh. Radionuclide Production. In, Principals of Nuclear Medicine. H. N. Wagner, Z. Szabo and J. W. Buchanan, Editors. W. B. Saunders Co., Philadelphia, 1995, 135.

[2] W. A. Volkert, W. F. Goeckeler, G. J. Ehrhardt, and A. R. Ketring. J. Nucl. Med. 32 (1991) 174

[3] L. M. Freeman, and M. D. Blaufoux, Editors: Radionuclide Therapy of Intractable Pain, Seminars In Nuclear Medicine XXII (1992), 58 pages.

[4] E. B. Silberstein: Doseage and Response in Radiopharmaceutical Therapy of Painful Osseous Metastases. J. Nucl. Med. 37 (1996) 249.

[5] F. F. Knapp, Jr., S. Guhlke, A. L. Beets, H. Amols, and J. Weinberger: J. Nucl. Card. 4, (1997) S-118.

[6] F. F. Knapp, Jr., S. Guhlke, A. L. Beets, H. Amols, and J. Weinbereger: J. Nucl. Med. 38,(1997) 124P.

[7] K. N. Geidd, H. Amols, C. Marboe, F. F. Knapp, Jr., and J. Weinberger: Circulation 96 (1997) I-220 (Abstract \# 1215).

[8] F. F. Knapp, Jr., S. Guhlke, A. L. Beets, M. Stabin, H. Amols and J. Weinberger. Circulation, submitted. 
[9] Directory of Nuclear Research Reactors 1994, International Atomic Energy Agency, Vienna, 1995 (TK 9202 D5X 1994).

[10] E. Dadachova, S. Mirzadeh, R. M. Lambrecht, E. L. Hetherington and F. F. Knapp, Jr.: Anal. Chem. 66 (1994) 4272.

[11] S. Mirzadeh, F. F. Knapp, Jr., C. W. Alexander, and L. F. Mausner: Appl. Radiat. Isot., 48 (1996) 441.

[12] F. F. Knapp, Jr., S. Mirzadeh: Eur. J. Nucl. Med. 21 (1994) 1151-1166.

[13] S. Mirzadeh, F. F. Knapp, Jr.: J. Radioanalyt. Nucl. Chem., 203 (1996), 471.

[14] M. M. Lambrecht, K. Tomiyoshi, and T. Sekine: Radiochim. Acta. 77 (1997) 103.

[15] F. F. Knapp, Jr., A. L. Beets, S. Guhlke, P. O. Zamora, H. Bender, H. Palmedo, and H.-J. Biersack: Antican. Res. 17 (1997) 1783

[16] F. F. Knapp, Jr., A. P. Callahan, A. L. Beets, S. Mirzadeh, and B.-T. Hsieh: Appl. Radiat. And Isot. 45 (1994) 1123.

[17] F. F. Knapp, Jr., S. Mirzadeh, and A. L. Beets: J. Radioanalyt. Nucl. Chem. Lett. 10 (1996) 19.

[18] F. F. Knapp, Jr., E. C. Lisic, S. Mirzadeh, A. P. Callahan, and D. E. Rice: In, Nuclear Medicine in Research and Practice, Schattauer Verlag, Stuutgart, Germany (1992) 183.

[19] F. F. Knapp, Jr., A. P. Callahan, A. L. Beets, S. Mirzadeh, and B.-T. Hsieh: Appl. Radiat. Isot. 45 (1994) 1123.

[20] S. Mirzadeh, F. F. Knapp, Jr., and A. P. Callahan: In, Proceedings of the International Conference on Nuclear Data for Science and Technology, S. M. Qaim, Editor, SpringerVerlag, New York (1992) 595. 
[21] S. Mirzadeh, F. F. Knapp, Jr., and R. M. Lambrecht: Radiochem. Acata 77 (1997) 99. . 
Table 1. Examples of Reactor-Produced Radioisotopes of Current Interest for Therapy

\begin{tabular}{|c|c|c|c|}
\hline Radioisotope & Half-life & Target & Comment \\
\hline Arsenic-77 (From Germanium-77) & 1.62 days & Ge-76 & Phosphorus Analogue \\
\hline Californium-252 & 2.645 years & Curium-244 $\rightarrow 248$ & Neutron Sources \\
\hline $\begin{array}{l}\text { Dysprosium-166 (Parent of } \\
\text { Holmium-166) }\end{array}$ & 3.4 days & Dy-164 & Synovectomy/Bone Pain \\
\hline Gold-199 (From Platinum-199) & 3.14 days & Pt-198 & Antibodies \\
\hline Holmium-166 & 26.8 hours & Ho-165 (nat.) & Various Therapeutic Applications \\
\hline Iridium-192 & 74.02 days & Ir-19I & Brachytherapy \\
\hline Lutetium-177 & 6.71 days & Lu-176 & Antibody Labeling \\
\hline Iodine-125 & 60 days & $\mathrm{Xe}-124$ & Therapy of Prostatic Carcinoma \\
\hline Osmium-194 & 6 years & Os-192 & Therapy research \\
\hline Palladium-103 & 16.96 days & Pd-102 & Therapy of Prostatic Carcinoma \\
\hline Phosphorus-32 & 14.29 days & S-32 & Multiple Applications \\
\hline Platinum- $193 m$ & 4.33 days & Pt-192 & Pharmaceutical Research \\
\hline Platinum-195m & 4.02 days & Pt-195 & Pharmaceutical Research \\
\hline Rhenium-186 & 3.77 days & Re-185 & Antibodies/Bone Pain Palliation \\
\hline Samarium-145 & 340 days & Sm-144 & Ocular Melanoma Therapy \\
\hline Samarium-153 & 1.93 days & Sm-152 & Bone Pain Palliation \\
\hline Scandium-47 & 3.42 days & $\mathrm{Ti}-46$ & Antibody Labeling \\
\hline Tin- $117 m$ & 13.6 days & Sn-116 or -117 & Bone Pain Palliation \\
\hline Strontium-89 & 50.55 days & Sr-88 & Bone Pain Palliation \\
\hline Silver-111 (From Palladium-111) & 7.47 days & $\mathrm{Pd}-110$ & Antibodies \\
\hline $\begin{array}{l}\text { Tungsten-188 (Rhenium-188 } \\
\text { Daughter) }\end{array}$ & 69 days & W-186 & $\begin{array}{l}\text { Bone Pain/Antibodies/ } \\
\text { Synovectomy }\end{array}$ \\
\hline
\end{tabular}


Table 2. Key Examples of Reactor-Produced Radioisotopes for Bone Pain Palliation

\begin{tabular}{||l|l|l|l|l||}
\hline \multicolumn{1}{|c|}{ Radioisotope } & $\begin{array}{c}\text { Half-Life } \\
\text { (Days) }\end{array}$ & $\begin{array}{c}\text { Beta Energy } \\
\text { (MeV) }\end{array}$ & $\begin{array}{l}\text { Gamma Energy, } \\
\text { keV (\%) }\end{array}$ & $\begin{array}{l}\text { Chemical Form } \\
\text { For Clinical Use }\end{array}$ \\
\hline Strontium-89 & 50.5 & 1.46 & None & Ionic - Chloride \\
\hline Phosphorus-32 & 14.3 & 1.71 & None & Phosphate \\
\hline Tin-117m & 13.6 & None, CE & $159(86 \%)$ & Sn(IV)-DTPA \\
\hline Samarium-153 & 1.93 & 0.81 & $103(28 \%)$ & EDTMP \\
\hline Rhenium-186 & 3.71 & 1.08 & $137(9.2 \%)$ & HEDP \\
\hline Rhenium-188 & 0.70 & 2.1 & $155(15 \%)$ & $\begin{array}{l}\text { HEDP, MDP, } \\
\operatorname{Re}(\mathrm{V})-D M S A\end{array}$ \\
\hline
\end{tabular}

$D T P A=$ Diethylenetriaminepentaacetic Acid

$E T D M P=$ Ethylenediaminetetramethylenephosphonate

$H E D P=$ Hydroxyethylidenediphosphonate

$M D P=$ Methylenediphosphonate

$D M S A=$ Dimercaptosuccinic Acid

Table 3 . Examples of Key Radionuclide Generators of Current Interest Prepared from reactor-Produced Parents Which Provide Therapeutic Daughter Radioisotopes

\begin{tabular}{|l|l|l|l|}
\hline \multicolumn{1}{|c|}{ Parent } & Daughter & \multicolumn{1}{|c|}{$\begin{array}{c}\text { Examples of Clinical } \\
\text { Applications }\end{array}$} & Comment \\
\hline Strontium-90 & Yttrium-90 & $\begin{array}{l}\text { Tumor Therapy, Bone Pain Palliation, } \\
\text { Introvascular Brachytherapy }\end{array}$ & $\begin{array}{l}\text { Advantage - long-lived and } \\
\text { readily available parent; } \\
\text { disadvantage - bone seekers }\end{array}$ \\
\hline Tungsten-188 & Rhenium-188 & $\begin{array}{l}\text { Tumor Therapy, Bone Pain Pailiation, } \\
\text { Introvascular Brachytherapy }\end{array}$ & $\begin{array}{l}\text { Advantage - efficient generator } \\
\text { with long shelf-life; disadvantage } \\
\text { - limited high-flux reactors for } \\
\text { W-188 production }\end{array}$ \\
\hline Dysprosium-166 & Holmium-166 & $\begin{array}{l}\text { Tumor Therapy, Bone Pain Palliation, } \\
\text { "In Vivo" Concept }\end{array}$ & $\begin{array}{l}\text { Advantage - useful high energy } \\
\text { beta; disadvantage - routine } \\
\text { separation difficult }\end{array}$ \\
\hline
\end{tabular}


Table 4 . Examples of Key Research Reactors Available for Production of Therapeutic Radioisotopes

\begin{tabular}{|c|c|l|l|}
\hline $\begin{array}{c}\text { Published Approximate } \\
\text { Maximum Thermal } \\
\text { Flux Values } \\
\text { Neutrons/cm²/sec/1014 }\end{array}$ & $\begin{array}{c}\text { Name of } \\
\text { Reactor }\end{array}$ & Institution & Country \\
\hline 50 & $S M 2$ & Dimitrovgrad & Russia \\
\hline 30 & $H F I R$ & ORNL & U.S. \\
\hline 12 & $B R 2$ & Mol & Beigium \\
\hline 10 & $A T R$ & INEL & U.S. \\
\hline 8 & $N R U$ & Nordion, Chalk River & Canada \\
\hline 8 & $H F B R$ & BNL & U.S. \\
\hline 5 & $M U R R$ & University of Missouri & U.S. \\
\hline 4 & $S A F A R I-1$ & Pelindaba & South Africa \\
\hline & & & \\
\hline
\end{tabular}

\section{Figure Legends}

Figure 1. Schematic of the top of the HFIR illustrating the target bundle located in the flux trap region.

Figure 2. Illustration of the target unit assembly in the flux trap region in which the Hydraulic Tube Assembly $(H T)$ and Peripheral Target Tubes $(P T P)$ are located. Each of the PTP tubes will accommodate a maximum of eight $H T$ tubes.

Figure 3. Photograph illustrating the target bundle and one PTP unit which fits into the outer housing of the target bundle.

Figure 4. Photograph of the new PTP target tube loading and unloading station which is being installed in the HFIR pool. 
ORNL-OWG 91M-8500

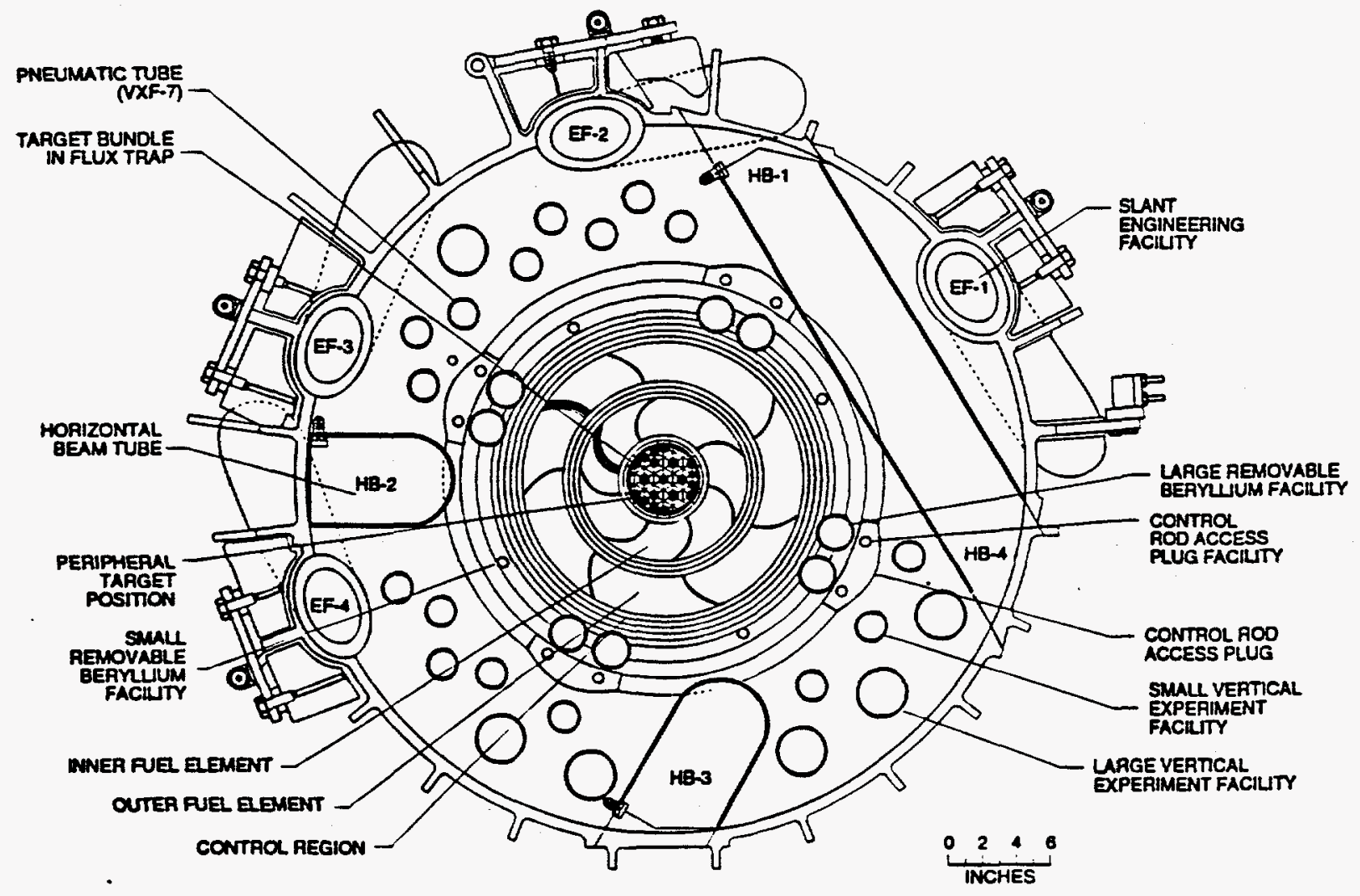


ORNL-DWG 91M-6491

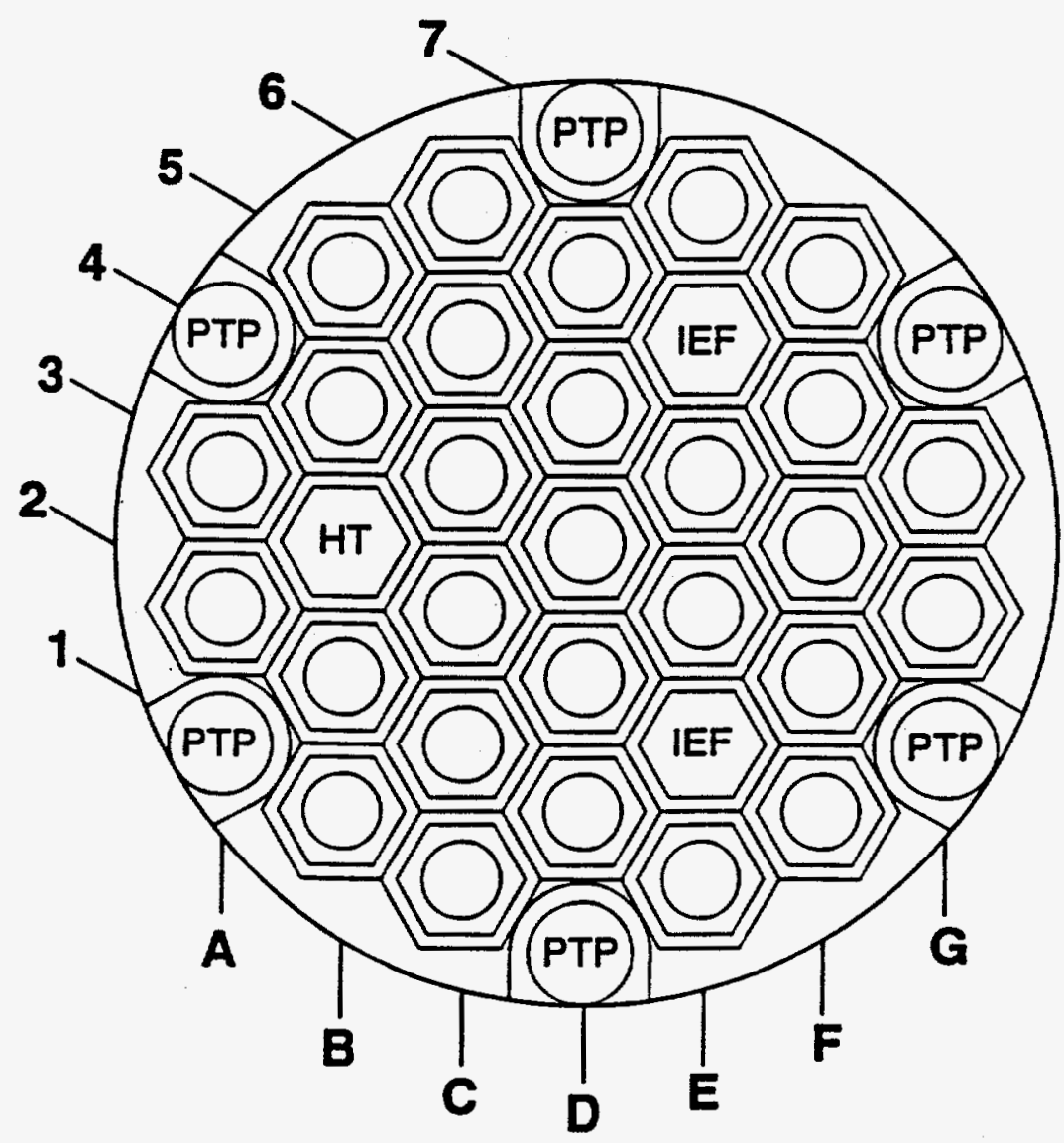

HT HYDRAULIC TUBE

PPT PERIPHERAL TARGET POSITIONS

IEF INSTRUMENTED

EXPERIMENT FACILITIES 


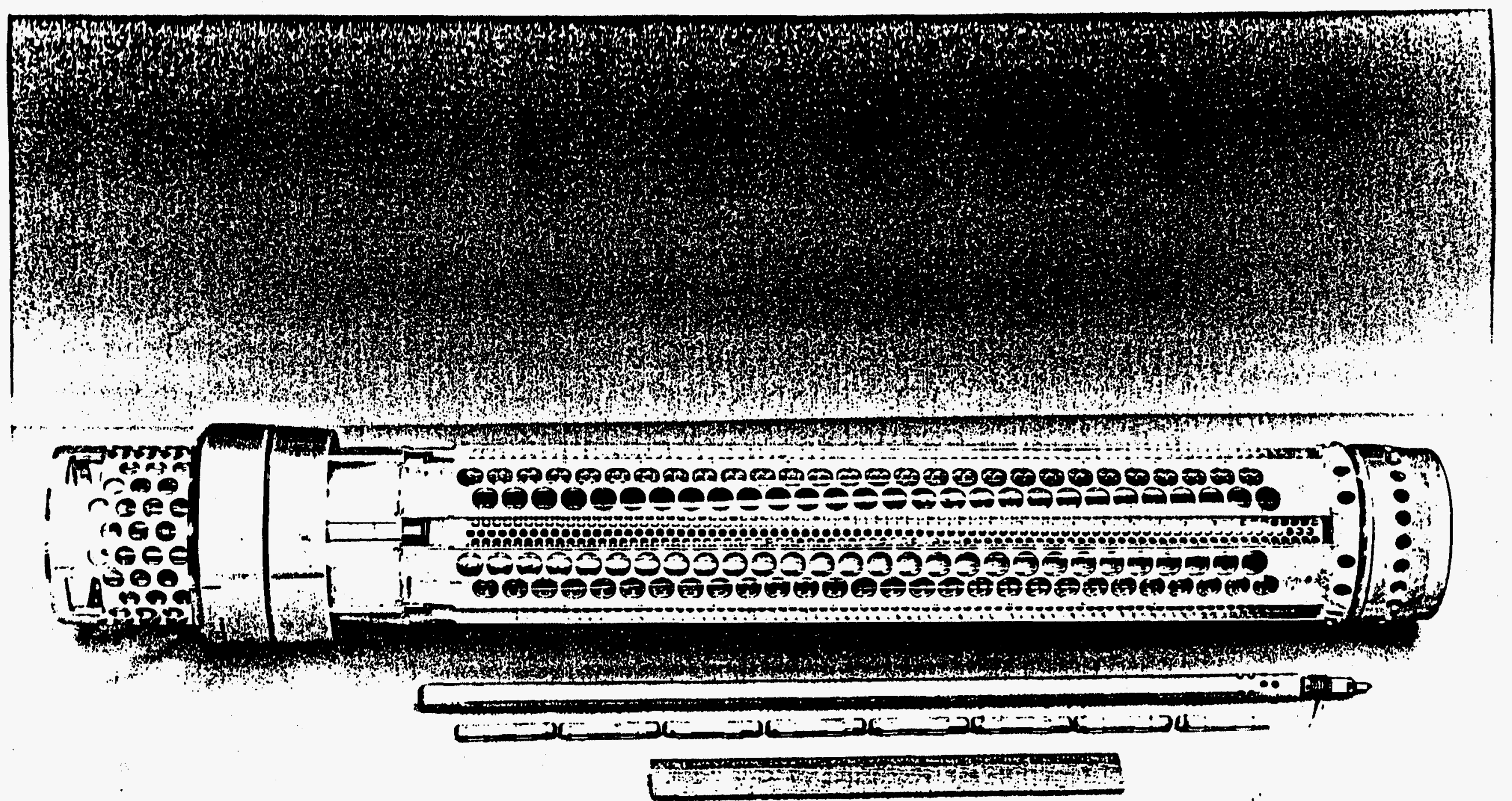




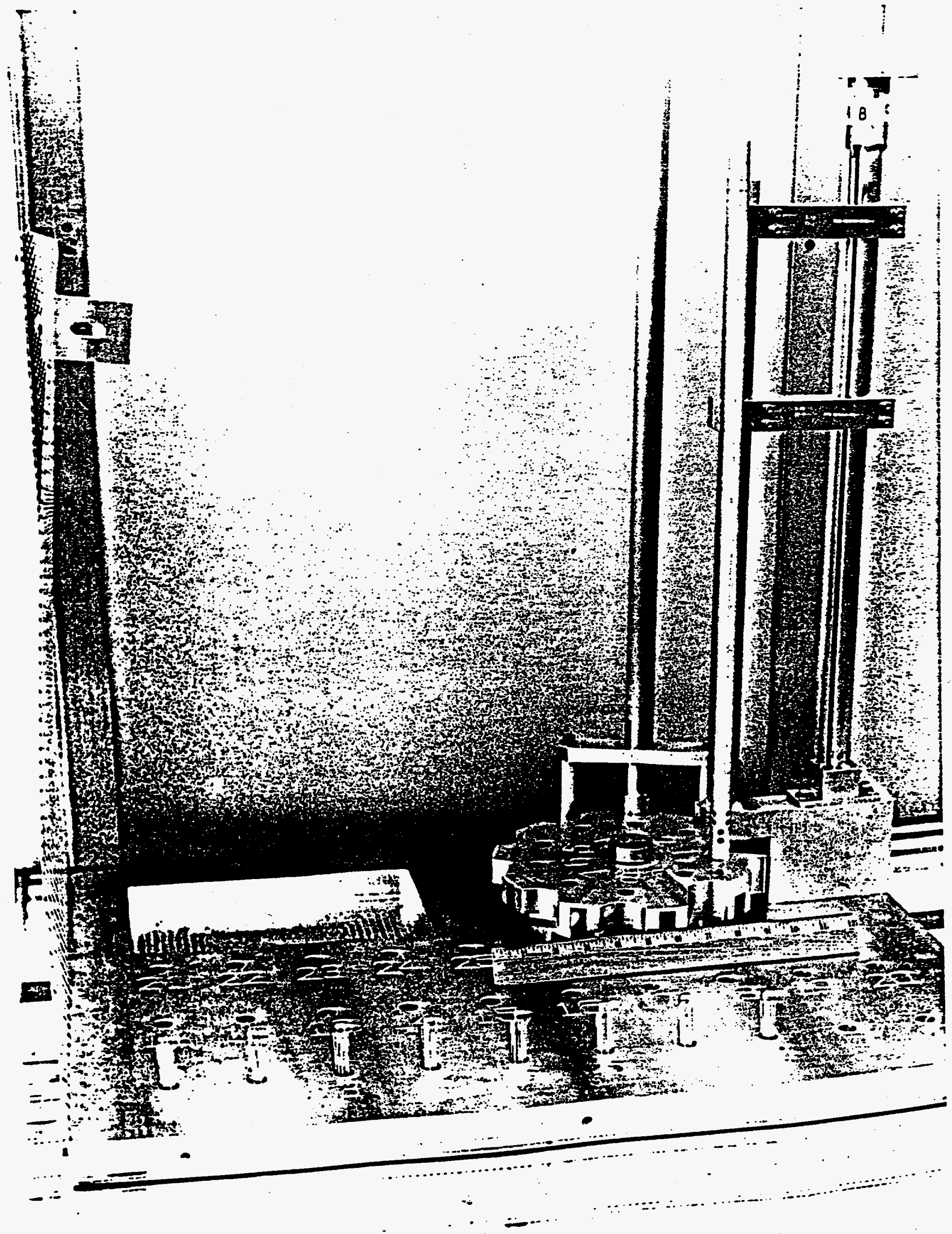

